\title{
Internal maxillary artery bypass for the treatment of complex middle cerebral artery aneurysms
}

\author{
Long Wang, MD, PhD, ${ }^{1,2}$ Shuaibin Lu, MD, ${ }^{3}$ Li Cai, MD, ${ }^{4,5}$ Hai Qian, MD, PhD, \\ Rokuya Tanikawa, MD, ${ }^{2}$ and Xiang'en Shi, MD, PhD ${ }^{1,6}$
}

'Department of Neurosurgery, SanBo Brain Hospital, Capital Medical University, Beijing, China; 2Department of Neurosurgery, Stroke Center, Teishinkai Hospital, Sapporo, Japan; '3Department of Neurosurgery, Beijing Shijingshan Hospital, Beijing, China; ${ }^{4}$ Department of Neurosurgery, The First Affiliated Hospital of University of South China, Hengyang, China; ${ }^{5}$ Arkansas Neuroscience Institute, St. Vincent Hospital, Little Rock, Arkansas; and 'Department of Neurosurgery, Fuxing Hospital, Capital Medical University, Beijing, China

OBJECTIVE The rapid innovation of the endovascular armamentarium results in a decreased number of indications for a classic surgical approach. However, a middle cerebral artery (MCA) aneurysm remains the best example of one for which results have favored microsurgery over endovascular intervention. In this study, the authors aimed to evaluate the experience and efficacy regarding surgical outcomes after applying internal maxillary artery (IMA) bypass for complex MCA aneurysms (CMCAAs).

METHODS All IMA bypasses performed between January 2010 and July 2018 in a single-center, single-surgeon practice were screened.

RESULTS In total, 12 patients (9 males, 3 females) with CMCAAs managed by high-flow IMA bypass were identified. The mean size of CMCAAs was $23.7 \mathrm{~mm}$ (range 10-37 mm), and the patients had a mean age of 31.7 years (range 14-56 years). The aneurysms were proximally occluded in 8 cases, completely trapped in 3 cases, and completely resected in 1 case. The radial artery was used as the graft vessel in all cases. At discharge, the graft patency rate was $83.3 \%(n=10)$, and all aneurysms were completely eliminated $(83.3 \%, n=10)$ or greatly diminished $(16.7 \%, n=2)$ from the circulation. Postoperative ischemia was detected in 2 patients as a result of graft occlusion, and 1 patient presenting with subarachnoid hemorrhage achieved improved modified Rankin Scale scores compared to the preoperative status but retained some neurological deficits. Therefore, neurological assessment at discharge showed that 9 of the 12 patients experienced unremarkable outcomes. The mean interval time from bypass to angiographic and clinical follow-up was 28.7 months (range 2-74 months) and 53.1 months (range 19-82 months), respectively. Although 2 grafts remained occluded, all aneurysms were isolated from the circulation, and no patient had an unfavorable outcome.

CONCLUSIONS The satisfactory result in the present study demonstrated that IMA bypass is a promising method for the treatment of CMCAAs and should be maintained in the neurosurgical armamentarium. However, cases with intraoperative radical resection or inappropriate bypass recipient selection such as aneurysmal wall should be meticulously chosen with respect to the subtype of MCA aneurysm.

https://thejns.org/doi/abs/10.3171/2018.11.FOCUS18457

KEYWORDS complex middle cerebral artery aneurysm; internal maxillary artery; high-flow bypass

$\mathrm{T}$ HE innovation of endovascular tools in clinical practice has put the indications for microsurgical repair in a constant state of ebb and flow. Although the treatment algorithm for intracranial aneurysms has been changed, microsurgery remains superior to endovascular therapy in the territory of the middle cerebral artery
(MCA), ${ }^{26}$ which is frequently involved with perforating lenticulostriate arteries (LSAs), coursing in a curved morphology and situated peripherally. ${ }^{11,17,20}$ In selected cases, direct clipping across the aneurysm neck without blood flow impairment may pose a technical challenge by virtue of the complex angioarchitecture. In such cases, complex

ABBREVIATIONS AR = aneurysmorrhaphy; CMCAA = complex MCA aneurysm; CTA = CT angiography; ECB = early cortical branch; EC-IC = extracranial-intracranial; FDD = flow diversion device; IMA = internal maxillary artery; $I_{2}=$ pterygoid segment of the IMA; LSA = lenticulostriate artery; $M C A=$ middle cerebral artery; mRS = modified Rankin Scale; $M_{1}=$ sphenoidal segment of the MCA; $M_{2}=$ insular segment of the MCA; $M_{3}=$ opercular segment of the MCA; RA = radial artery; SAH = subarachnoid hemorrhage; STA = superficial temporal artery.

SUBMITTED September 7, 2018. ACCEPTED November 14, 2018.

INCLUDE WHEN CITING DOI: 10.3171/2018.11.FOCUS18457. 
MCA aneurysms (CMCAAs) continue to require bypasses as part of a curative treatment strategy with deliberate occlusion.

Recently, the internal maxillary artery (IMA) bypass, the only substantive modification of cerebral revascularization techniques, has gained momentum. ${ }^{24,25,32-34,36}$ This technique was heralded as a new "workhorse" in the field of high-flow bypass to replace conventional cervical artery bypass. ${ }^{14,29}$ However, very limited data exist regarding the experiences with using this novel extracranial artery as a donor, especially in the territory of the MCA. In the present study, we aimed to investigate the surgical outcomes of IMA bypass in the treatment of CMCAAs.

\section{Methods \\ Data Collection}

This study retrospectively evaluates our experience using an IMA bypass to treat CMCAAs between January 2010 and July 2018. The protocol was approved by the institutional review board and ethics committee of SanBo Brain Hospital, Capital Medical University. An informed consent form was signed by all patients and documented in each case. The patient demographic and clinical data were extracted from our electronic medical record system. The following data were collected: demographic information; clinical parameters (aneurysm characteristics, antiplatelet and anticoagulation regimens, and operative reports); radiographic studies; intraoperative measurement data and images; and outpatient clinical data. An experienced investigator who was blinded to the patients' clinical characteristics independently reviewed all the data. The patients' characteristics are given in Table 1.

\section{IMA Bypass Decision-Making}

The treatment strategy is tailored on a case-by-case basis by multiple considerations, including patient age, family history of subarachnoid hemorrhage (SAH), medical comorbidities, and psychological impact of aneurysm (morphology, location, size, rupture status). The MCA aneurysms that related to at least 2 of the following features were defined as complex in character: 1) size $>2.5 \mathrm{~cm} ; 2$ ) aneurysm angioanatomy (involvement of critical perforating or branch vessels); 3 ) previous treatment (endovascular or surgical); 4) complex morphology (fusiform, dissecting, serpentine, and dolichoectatic); 5) intraluminal thrombosis; or 6) atherosclerotic plaques and calcifications of the aneurysm wall and/or neck. Both surgical and endovascular treatment options are offered.

Therapeutic alternatives were discussed after diagnostic angiography among neurosurgeons, neurointerventionalists, and neurovascular neurologists in a multidisciplinary decision-making process. Patients and families had the freedom to choose a therapy. However, if direct clipping/clip reconstruction or neurointerventional treatment was deemed futile on the basis of preoperative imaging findings, patients were directly recommended for cerebral bypass.

The type of bypass performed in the MCA territory depended on the aneurysm origin, LSA involvement, caliber and location of the occluded artery, viability of the collat- eral circulation, and the potential graft flow. The high-flow extracranial-intracranial (EC-IC) bypass was preferred to achieve the deliberate occlusion of large-diameter arteries (prebifurcation or bifurcation lesions), whereas low-flow bypass was first considered for distal MCA lesions. The cervical high-flow bypass has been replaced by the novel IMA bypass due to the avoidance of a second incision, short graft, and well-matched caliber. Considering many false-negative results, the balloon temporary occlusion test was rarely used in our series and did not affect our strategies.

\section{MCA Aneurysm Location}

The aneurysm location was divided into 4 subtypes according to a new classification:7,11 1) sphenoidal segment of the MCA $\left.\left(\mathrm{M}_{1}\right)-\mathrm{LSA} ; 2\right) \mathrm{M}_{1}$-early cortical branch (ECB) (i.e., $\mathrm{M}_{1}$ aneurysms arising on $\mathrm{M}_{1}$ at the origin of early frontal or temporal ECB); 3) MCA bifurcation or trifurcation aneurysm; and 4) distal MCA aneurysms that arise on the insular, opercular, or cortical segments of the MCA. However, in our series, a majority of cases manifested with complex characteristics, and specific location was determined in a setting of multidisciplinary discussion.

\section{Bypass Technique and Perioperative Management}

The techniques of performing IMA bypass have been described in our previous articles..$^{24,25,29,32-34,36}$ Briefly, we approached the aneurysms using a frontotemporal craniotomy with zygomatic osteotomy. The radial artery (RA) was harvested and prepared before being anastomosed in an end-to-end fashion to the pterygoid segment of the IMA $\left(I_{2}\right)$ by using 9-0 prolene. The free end of the RA was then brought to the sylvian fissure and anastomosed to the insular segment of the MCA $\left(\mathrm{M}_{2}\right)$ by using 9-0 sutures in an end-to-side manner. The aneurysm located after the bypass takeoff was then resected or trapped with a permanent aneurysm clip or ligation.

For patients without a history of SAH, $300 \mathrm{mg}$ of aspirin was given 3 days prior to the procedure. During the procedure, neurophysiological monitoring was used to identify cerebral ischemia during temporary occlusion of the parent artery. Doppler flow measurements (PRO Focus 2202, BK Medical) and indocyanine green videoangiography were used to analyze the adequacy of treatment and patency of parent vessels. After the procedure, all patients were monitored overnight in a neurointensive care unit under the supervision of neurosurgeons, and blood pressure was kept 10\%-20\% higher than the baseline. On postoperative day 2 , subcutaneous anticoagulation with low-molecular-weight heparin was prescribed for 3 consecutive days, and then patients were kept on $300 \mathrm{mg}$ of aspirin per day as in the preoperative algorithm. Three months after the procedure, each patient was maintained on a 100-mg single daily dose of aspirin. Patients were loaded with 1.0 $\mathrm{mg} / \mathrm{hr}$ nimodipine for 7-10 days after the intervention.

\section{Imaging Analysis and Follow-Up}

Postoperative and 3D CT angiography (CTA), which was evaluated independently by neuroradiologists, was scheduled at 6-8 hours after treatment to confirm the 
TABLE 1. Clinical characteristics of 12 patients with CMCAAs treated by IMA bypass

\begin{tabular}{|c|c|c|c|c|c|c|c|c|c|c|c|c|c|}
\hline \multirow[b]{2}{*}{$\begin{array}{l}\text { Case } \\
\text { No. }\end{array}$} & \multirow{2}{*}{$\begin{array}{l}\text { Age } \\
\text { (yrs)/ } \\
\text { Sex }\end{array}$} & \multirow[b]{2}{*}{$\begin{array}{c}\text { Initial } \\
\text { Presentation }\end{array}$} & \multirow{2}{*}{$\begin{array}{l}\text { Aneurysm } \\
\text { Location, } \\
\text { Morphology }\end{array}$} & \multirow[b]{2}{*}{$\begin{array}{l}\text { Size } \\
(\mathrm{mm})\end{array}$} & \multirow[b]{2}{*}{$\begin{array}{l}\text { Aneurysm } \\
\text { Treatment }\end{array}$} & \multicolumn{3}{|c|}{ mRS Score } & \multicolumn{2}{|c|}{$\begin{array}{l}\text { Bypass } \\
\text { Patency }\end{array}$} & \multicolumn{2}{|c|}{$\begin{array}{l}\text { Aneurysm } \\
\text { Outcome }\end{array}$} & \multirow[b]{2}{*}{ Complications } \\
\hline & & & & & & Preop & Postop & $\begin{array}{l}\text { At FU } \\
\text { (mos) }\end{array}$ & Postop & $\begin{array}{l}\text { At FU } \\
\text { (mos) }\end{array}$ & Postop & $\begin{array}{l}\text { At FU } \\
\text { (mos) }\end{array}$ & \\
\hline 1 & $44 / \mathrm{M}$ & $\mathrm{FN}$ & $M_{1}-L S A$, fusiform & 13 & $P O+A R$ & 1 & 2 & $0(82)$ & $\mathrm{Pa}$ & $\mathrm{Pa}(74)$ & TE & TE (74) & No \\
\hline 2 & $40 / F$ & Headache & $\begin{array}{l}\text { MCA bifurcation, } \\
\text { fusiform }\end{array}$ & 12 & $\mathrm{PO}$ & 1 & 3 & $1(75)$ & Oc & Oc (58) & TE & TE (58) & $\begin{array}{l}\text { Cerebral } \\
\text { ischemia }\end{array}$ \\
\hline 3 & $56 / F$ & SAH (H \& H II) & $\mathrm{M}_{1}-\mathrm{ECB}$, fusiform & 10 & $\mathrm{PO}+\mathrm{AR}$ & 4 & 3 & $0(70)$ & $\mathrm{Pa}$ & $\mathrm{Pa}(43)$ & TE & TE (43) & No \\
\hline 4 & $33 / \mathrm{M}$ & SAH (H \& H III) & $M_{1}-M_{2}$, thrombosed & 26 & Trapping & 4 & 2 & $0(63)$ & $\mathrm{Pa}$ & $\mathrm{Pa}(48)$ & TE & TE (48) & No \\
\hline 5 & $21 / \mathrm{M}$ & Headache & $\mathrm{M}_{1}-\mathrm{M}_{3}$, thrombosed & 29 & $\mathrm{PO}$ & 1 & 0 & $0(61)$ & $\mathrm{Pa}$ & $\mathrm{Pa}(5)$ & GD & TE (5) & No \\
\hline 6 & $22 / \mathrm{M}$ & Headache & $M_{1}-M_{2}$, fusiform & 22 & Trapping & 1 & 2 & $1(55)$ & $\mathrm{Pa}$ & $\mathrm{Pa}(3)$ & TE & TE (3) & No \\
\hline 7 & $23 / \mathrm{M}$ & Headache & $M_{1}-E C B$, recurrent & 33 & $\begin{array}{l}\text { Trapping } \\
\quad+\text { AR }\end{array}$ & 1 & 0 & $0(53)$ & $\mathrm{Pa}$ & $\mathrm{Pa}(25)$ & TE & TE (25) & No \\
\hline 8 & $30 / \mathrm{M}$ & Headache & $\begin{array}{l}\text { MCA bifurcation, } \\
\text { thrombosed }\end{array}$ & 26 & Resection & 1 & 4 & $0(52)$ & Oc & Oc (50) & TE & TE (50) & $\begin{array}{l}\text { Cerebral } \\
\quad \text { ischemia }\end{array}$ \\
\hline 9 & $29 / M$ & SAH (H \& H II) & $\begin{array}{l}\mathrm{M}_{1}-\mathrm{ECB} \text {, fusiform, } \\
\text { thrombosed }\end{array}$ & 17 & $\mathrm{PO}$ & 3 & 2 & $1(47)$ & $\mathrm{Pa}$ & $\mathrm{Pa}(20)$ & TE & TE (20) & No \\
\hline 10 & $31 / \mathrm{M}$ & Dizziness & $\mathrm{M}_{2}$, serpentine & 37 & PO & 1 & 1 & $0(35)$ & $\mathrm{Pa}$ & $\mathrm{Pa}(11)$ & GD & TE (11) & No \\
\hline 11 & $14 / \mathrm{M}$ & Seizure & $\begin{array}{l}\mathrm{M}_{1}-\mathrm{LSA} \text {, fusiform, } \\
\text { thrombosed }\end{array}$ & 23 & $\mathrm{PO}$ & 0 & 0 & $0(25)$ & $\mathrm{Pa}$ & $\mathrm{Pa}(5)$ & TE & $\mathrm{TE}(5)$ & No \\
\hline 12 & $37 / F$ & Headache & $\begin{array}{l}M_{1}-M_{2}, \text { fusiform, } \\
\text { thrombosed }\end{array}$ & 36 & $\mathrm{PO}$ & 1 & 2 & $0(19)$ & $\mathrm{Pa}$ & $\mathrm{Pa}(2)$ & TE & $\mathrm{TE}(2)$ & No \\
\hline
\end{tabular}

$\mathrm{FN}=$ facial numbness; $\mathrm{FU}=$ follow-up; $\mathrm{GD}=$ greatly diminished; $\mathrm{H} \& \mathrm{H}=$ Hunt and Hess; $\mathrm{Oc}=$ occlusion; $\mathrm{Pa}=$ patent; $\mathrm{PO}=$ proximal occlusion; TE = total elimination.

patency of the graft conduit and to look for hemorrhagic complications. If worsening neurological function was observed, multimodal MRI was performed immediately to identify territorial ischemia. The aneurysm stability was classified as complete occlusion/obliteration (no residual aneurysm), greatly diminished (residual neck), or incomplete occlusion (aneurysm lumen remaining). The followup cerebral angiogram was performed after 3 months, and then yearly thereafter.

The neurological outcomes were assessed using a modified Rankin Scale (mRS) by one of the authors (S.L.) in a blinded fashion, and the scores were recorded. Followup functional outcome was measured based on telephone interviews with the patient or, if the patients were unable to participate, their relatives or primary caregivers were asked to provide information. If complications occurred, mRS scores were determined on an outpatient visit with physical examination.

\section{Results}

\section{Patients and Aneurysm Characteristics}

During an 8-year period, 12 consecutive patients harboring CMCAAs were treated by IMA bypass; the group included 9 males and 3 females. The average age of patients was 31.7 years, with a range of $14-56$ years. The most common presentation that led to the diagnosis was headache. Other presenting symptoms varied, and included facial numbness, dizziness, and seizure. SAH was observed in 3 patients, of which 2 were Hunt and Hess grade II and 1 was Hunt and Hess grade III. One patient had a thrombosed giant aneurysm following a first attempt at treatment. The pretreatment mRS score (mean 1.6; range $0-4$ ) was $0-1$ for 9 patients and 3-4 for 3 patients.

The mean size of the CMCAA was $23.7 \mathrm{~mm}$ (range $10-37 \mathrm{~mm})$, and all the aneurysms were large $(\mathrm{n}=6)$ or giant $(n=6)$. Two aneurysms were located at the $M_{1}-$ LSA segment, 3 at the $\mathrm{M}_{1}-\mathrm{ECB}$ segment, 2 at the MCA bifurcation, 1 at the distal MCA segment, and 4 extensively involved the MCA. Treated lesions presented with fusiform morphology in 7 patients, thrombotic in 6 patients, serpentine in 1 patient, and recurrent after a primary attempt in 1 patient. The baseline patient and aneurysm characteristics are summarized in Table 2.

\section{Immediate and Long-Term Outcomes of IMA Bypass Surgery}

The proximal occlusion of the parent artery following IMA bypass was attained in 8 cases $(75 \%)$ with $(n=2)$ or without $(\mathrm{n}=6)$ aneurysmorrhaphy (AR). The remaining aneurysms were completely trapped with $(n=1)$ or without $(\mathrm{n}=2)$ AR or completely resected $(\mathrm{n}=1)$. Intraoperative complications, such as unexpected rupture, were not observed. Of the 12 patients who were initially included in this study, $10(83.3 \%)$ achieved complete aneurysm elimination on immediate angiographic results, and the aneurysms of the other $2(16.7 \%)$ were greatly diminished. Postoperative angiograms documented graft patency in 10 of 12 patients $(83.3 \%)$. Surgery-related deaths did not occur in the perioperative period. The mRS score (mean 1.7; range $0-4$ ) at discharge was $0-2$ in 9 patients and 3-4 in 3 patients, which was equal to the preoperative status. Three patients had unfavorable outcomes, of whom 2 had 
TABLE 2. Summary of baseline patient and aneurysm characteristics in 12 patients with CMCAAs

\begin{tabular}{|c|c|}
\hline Variable & Value \\
\hline \multicolumn{2}{|l|}{ Background characteristics } \\
\hline \multicolumn{2}{|l|}{ Sex } \\
\hline Male & 9 \\
\hline Female & 3 \\
\hline Mean age, yrs (range) & $31.7(14-56)$ \\
\hline Mean size, mm (range) & $23.7(10-37)$ \\
\hline \multicolumn{2}{|l|}{ Location } \\
\hline$M_{1}-L S A$ & 2 \\
\hline$M_{1}-E C B$ & 3 \\
\hline Bifurcation & 2 \\
\hline Distal & 1 \\
\hline Extended involvement & 4 \\
\hline \multicolumn{2}{|c|}{ Presenting aneurysm characteristic } \\
\hline \multicolumn{2}{|l|}{ Size } \\
\hline Large & 6 \\
\hline Giant & 6 \\
\hline \multicolumn{2}{|l|}{ Complexity } \\
\hline Fusiform & 7 \\
\hline Thrombotic & 6 \\
\hline Serpentine & 1 \\
\hline Recurrent & 1 \\
\hline \multicolumn{2}{|l|}{ History of SAH } \\
\hline $\mathrm{H} \& \mathrm{HII}$ & 2 \\
\hline $\mathrm{H} \& \mathrm{H} I I I$ & 1 \\
\hline Mean mRS score (range) & $1.6(0-4)$ \\
\hline
\end{tabular}

new permanent neurological deficits by virtue of the graft occlusion and 1 was slightly disabled as reflected in the poor Hunt and Hess status. The angiographic and clinical outcomes after the procedure are summarized in Table 3.

No adverse events (patient death, posttreatment rupture, or aneurysm recurrence) were observed during hospitalization and follow-up. In the angiographic follow-up study (mean 28.7 months; range 2-74 months), patent RA was found in $83.3 \%(n=10)$ of patients, and the complete occlusion rate of aneurysms was $100 \%$. The median duration of follow-up focusing on neurological functions was 53.1 months (range 19-82 months), and excellent outcomes were achieved in all patients (mRS score: mean 0.3; range $0-1$ ). Regarding the cosmetic issue in the region of the temporalis muscle, no patient complained of fullness and discomfort at a level that was bothersome enough to merit intervention. The outcomes at long-term follow-up are summarized in Table 4.

\section{Illustrative Cases}

A 37-year-old woman (case 12) was admitted to our department with a 1-month history of severe headache, and a mass lesion in the sylvian fissure was detected. Her past medical history was unremarkable, and neurological examination on admission revealed no focal deficits. Pre-
TABLE 3. Postoperative results of IMA bypass surgery in 12 patients with CMCAAs

\begin{tabular}{|c|c|}
\hline Description & No. $(\%)$ \\
\hline \multicolumn{2}{|l|}{ Aneurysm manipulation } \\
\hline Parent artery occlusion & 8 \\
\hline w/AR & 2 \\
\hline w/o AR & 6 \\
\hline Trapping & 3 \\
\hline W/ AR & 1 \\
\hline w/o AR & 2 \\
\hline Resection & 1 \\
\hline \multicolumn{2}{|l|}{ Graft patency } \\
\hline $\mathrm{Pa}$ & $10(83.3)$ \\
\hline Occluded & $2(16.7)$ \\
\hline \multicolumn{2}{|l|}{ Aneurysmal morphology } \\
\hline TE & $10(83.3)$ \\
\hline GD & $2(16.7)$ \\
\hline \multicolumn{2}{|l|}{ Clinical outcomes } \\
\hline Mean mRS score & 1.7 , range $0-4$ \\
\hline $0-2$; favorable & $9(75.0)$ \\
\hline $3-5 ;$ poor & $3(25.0)$ \\
\hline 6; died & $0(0)$ \\
\hline \multicolumn{2}{|l|}{ Surgery-related complication } \\
\hline Cerebral ischemia & $2(16.7)$ \\
\hline
\end{tabular}

operative CTA (Fig. 1) was performed and confirmed a giant, fusiform, thrombosed aneurysm that involved the $\mathrm{M}_{1}-\mathrm{M}_{2}$ segment of the MCA. Following a multidisciplinary discussion, microsurgical repair or endovascular treatment modalities were deemed likely to fail. Therefore, a high-flow IMA bypass was considered, followed by parent artery occlusion to preserve the perforators arising from the aneurysm wall. The RA was harvested and prepared after confirmation of the Allen test, and the

TABLE 4. Long-term outcomes of IMA bypass surgery in 12 patients with CMCAAs

\begin{tabular}{lc}
\hline Long-Term Outcome & No. (\%) \\
\hline Angiographic & \\
\hline Mean time in mos, range & $28.7,2-74$ \\
\hline Graft patency & $10(83.3)$ \\
\hline Pa & $2(16.7)$ \\
\hline Occluded & \\
\hline Aneurysm morphology & $12(100)$ \\
\hline TE & \\
\hline Clinical & $53.1,19-82$ \\
\hline Mean time in mos, range & $0.3,0-1$ \\
\hline Mean mRS score, range & 12 \\
\hline Favorable & $9(75)$ \\
\hline mRS 0 & $3(25)$ \\
\hline mRS 1
\end{tabular}



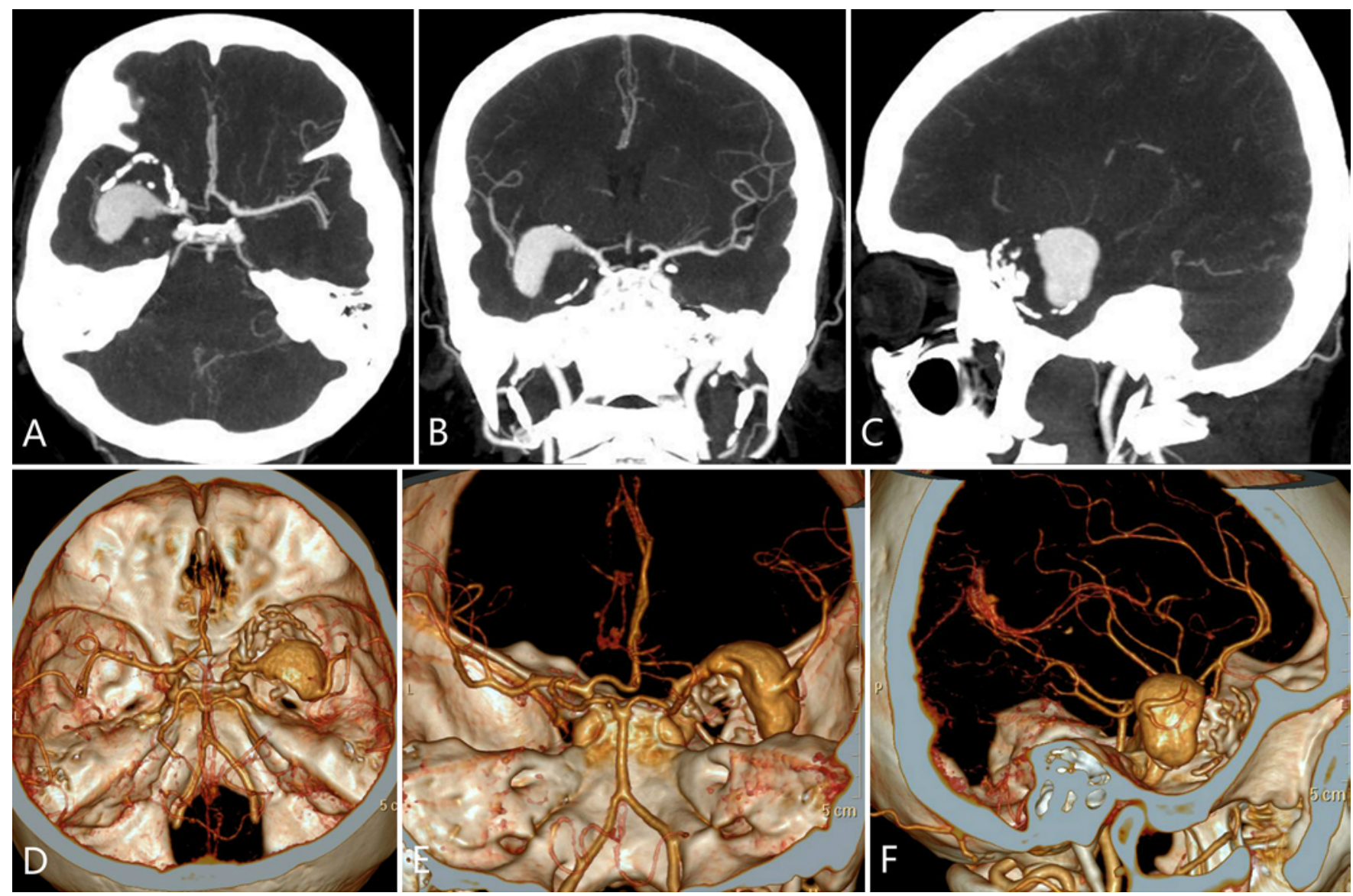

FIG. 1. Preoperative axial (A), coronal (B), and sagittal (C) CTA demonstrated a giant $(36 \times 25 \times 25 \mathrm{~mm})$, thrombosed, fusiform MCA aneurysm. 3D CTA (D-F) images were then reconstructed to identify the specific location of the aneurysm involving the $\mathrm{M}_{1}-\mathrm{M}_{2} \mathrm{MCA}$ segment.

aneurysm was approached using a frontotemporal craniotomy with zygomatic osteotomy to expose the $\mathrm{I}_{2}$. The extracranial IMA-RA bypass was initially performed in an end-to-end manner, and then the free end of the RA was anastomosed to the $\mathrm{M}_{2}$ in an end-to-side manner. Following the bypass, patency was confirmed by intraoperative Doppler ultrasonography and indocyanine green, and the proximal part of $\mathrm{M}_{1}$ was occluded with a permanent aneurysm clip (Aesculap Instruments Corp.) (Fig. 2). Complete elimination of the aneurysm with a patent graft artery was confirmed by postoperative angiography (Fig. 3), and the patient was discharged, having attained independent status (mRS score of 2). She underwent follow-up evaluation at 19 months after surgery through an outpatient visit without exhibiting any functional neurological limitations (mRS score of 0$)$.

\section{Complications and Clinical Impact}

Two patients experienced permanent neurological worsening after IMA bypass. The first patient (case 2 ) had an MCA bifurcation aneurysm (Fig. 4A and B), and the atherosclerotic nature of the lesion was noted intraoperatively (Fig. 4C). Following the primary attempt at arterial reconstruction between $\mathrm{RA}$ and temporal $\mathrm{M}_{2}$, stenosis of the anastomosis site was detected immediately. The by- pass was disassembled and the opening of temporal $\mathbf{M}_{2}$ was sutured. The $\mathrm{M}_{2}$ segment of the aneurysm wall was then chosen as a recipient, and microsurgical anastomosis was performed uneventfully in an end-to-side fashion. Neurophysiological monitoring showed no change during the bypass, and Doppler imaging identified patency of the graft with abundant distal flow. However, the patient's functions gradually decreased, and neuroimaging demonstrated left frontotemporal ischemia with severe vasospasm of the RA (Fig. 4D-F). Mannitol and nimodipine were then prescribed for conservative management. Although the patient had weakness of the right extremity (muscle strength grade 2) at discharge with moderate disability (mRS score of 3 ), her symptoms were completely resolved without neurological deficits (mRS score of 1) at the last follow-up.

In the second patient (case 8), a giant MCA bifurcation aneurysm was resected following IMA-RA-temporal $\mathrm{M}_{2}$ bypass. Although the perforators that arose from the aneurysm wall were not observed, the proximal $\mathrm{M}_{1}$ segment that was involved in the lesion was partially sacrificed intraoperatively. Postoperative CTA revealed graft occlusion, and the patient experienced left hemiparesis on postoperative day 7 . The basal ganglia infarction was verified by neuroimaging with the suspicion of $\mathrm{M}_{1}$ perforating 

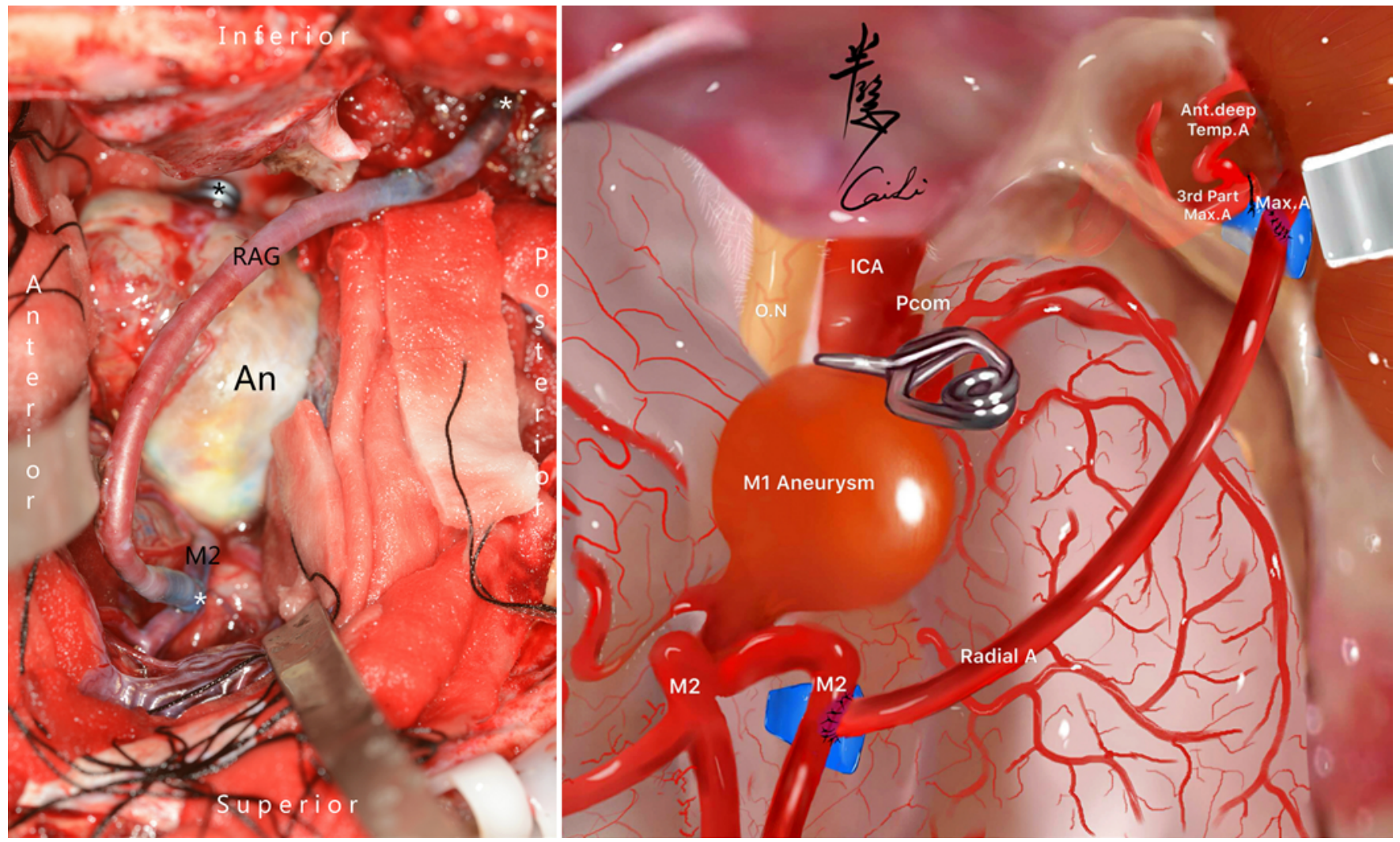

FIG. 2. IMA-RA-M $\mathrm{M}_{2}$ bypass was performed followed by proximal occlusion of the aneurysm. An intraoperative picture (left) showing 2 anastomosis sites (white asterisks) and clip ligation of proximal $\mathrm{M}_{1}$ (black asterisk). Artist's rendering (right) of the patient's microsurgical treatment with IMA bypass for the management of CMCAA. $A n=$ aneurysm; $A n t .=$ anterior; Max. $A=$ maxillary artry; $\mathrm{O} . \mathrm{N}=$ optic nerve; Pcom = posterior communicating artery; RAG = right arterial graft; Temp. $\mathrm{A}=$ temporal artery. Copyright Li Cai (right panel). Published with permission.

artery thrombosis. The patient was discharged with severe disability (mRS score of 4) but recovered uneventfully during the 4-year follow-up.

These 2 occlusion cases that resulted in temporary neurological deficits could be explained by the perforator sacrifice and inappropriate recipient site selection.

\section{Discussion}

This study of 12 patients with IMA bypasses for the CMCAAs observed on immediate angiographic sequences showed that the patency rate was $83.3 \%$ and that all the aneurysms were removed from the circulation. In 2 cases (16.7\%) our patients experienced ischemic events that resulted in new permanent neurological deficits. In one case the surgeon had used the aneurysm wall as the recipient, and the other aneurysm was resected intraoperatively, which may compromise the surrounding perforators. However, over a long-term follow-up, all patients experienced unremarkable outcomes, and negative events (aneurysm recurrence or late-phase bleeding) were not encountered. We emphasize that radical aneurysm resection or using the aneurysm wall as a recipient should be avoided. To our knowledge, this represents the largest case series reported to date, and no previous study has attempted to describe the failed experience with IMA bypass. Our results predict that, even in the endovascular era, high-flow bypass retains an essential role for complex cerebrovascular disorders.

\section{Endovascular Treatment of CMCAAs}

Recently, techniques in which flow diversion devices (FDDs) are used to treat complex cerebrovascular diseases have documented acceptable safety profiles, which result in a decrease in the number of indications for a classic surgical approach. ${ }^{11}$ However, the treatment results remain suboptimal in the territory of the MCA, which should be evaluated as a separate entity for the following reasons. ${ }^{3,4,40}$ First, the estimated proportion of MCA aneurysms that are amenable to treatment with the FDD was only $5 \% .^{2}$ Moreover, this device is not currently indicated for aneurysms on tortuous sidewall or end-wall bifurcations, ${ }^{2,3,5}$ and those arising from bifurcation represent $85 \%$ of all MCA aneurysms. ${ }^{40}$ Even with the latest-generation devices, there is in vitro and in vivo experimental evidence that FDDs are more prone to fail..$^{5,6}$ As for MCA aneurysms, perforator injury is another potential concern. ${ }^{3,40}$ FDDs often cover or "jail" side branches, which can cause unintended occlusions and ischemic complications. ${ }^{20,22,26,40}$ The rate of side-branch occlusion was strongly associated with bi- 

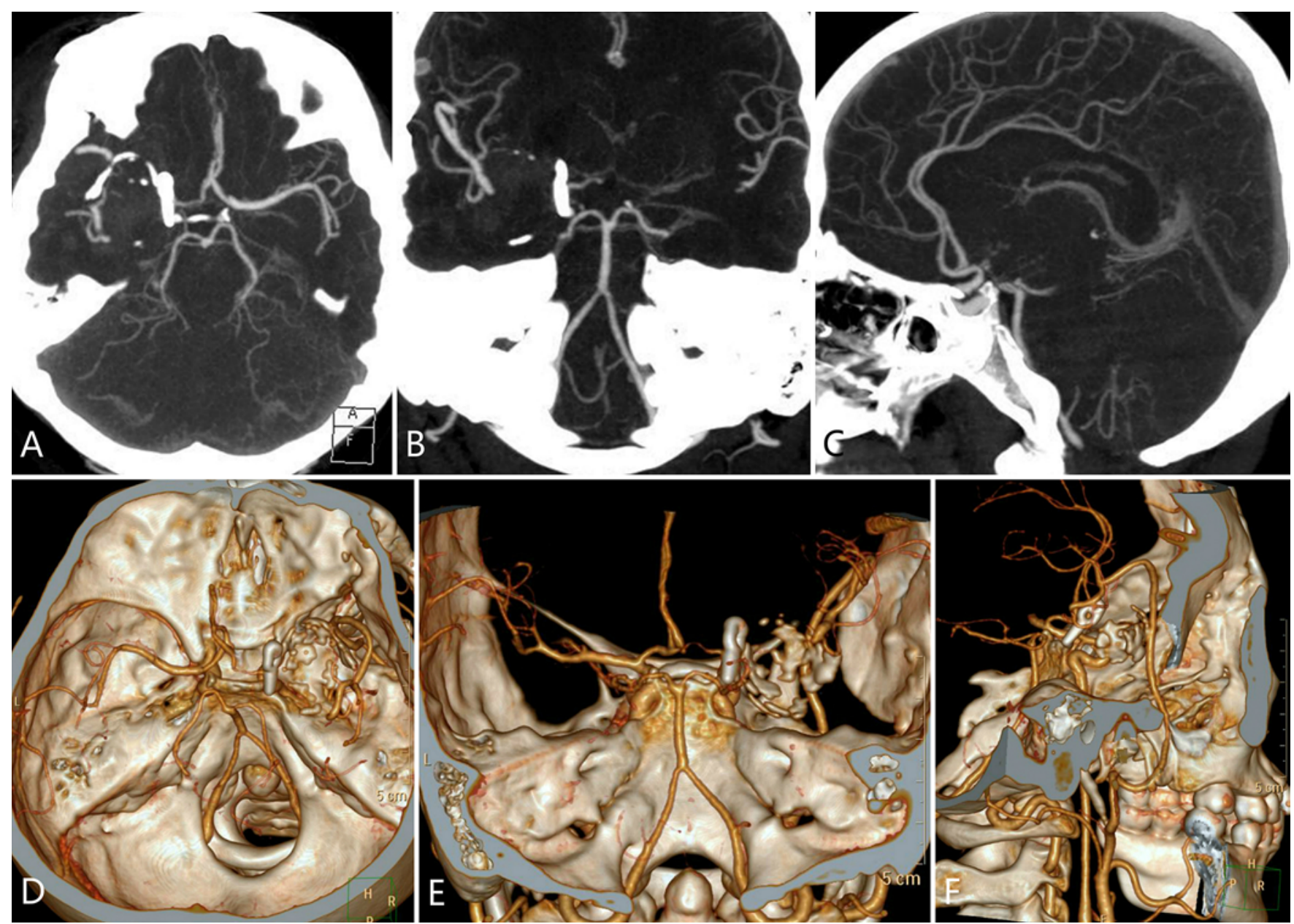

FIG. 3. Postoperative axial (A), coronal (B), and sagittal (C) CTA confirmed the total elimination of the aneurysm, and 3D CTA (D-F) illustrated the patent status of the graft vessel, with robust distal flow.

furcation aneurysms. ${ }^{28}$ In addition, delayed hemorrhage and aneurysm rupture are complications that must be factored into the treatment algorithm. ${ }^{3}$ The requirement for antiplatelet agents also limits their application in patients with a history of rupture. ${ }^{20}$ Another major concern is the high recanalization and retreatment rates,, 56 as well as the high risk of incomplete occlusion, ${ }^{11,40}$ which may render the endovascular method ineffective. Therefore, we should also remind ourselves that the clinical course after FDD placement is not inevitably benign or without risk, and the morbidity and mortality rates associated with these endovascular series consistently exceeded those reported by experienced microneurosurgeons. ${ }^{17}$

\section{Microsurgical Selection for CMCAAs}

The primary treatment strategy for MCA aneurysms remains microsurgical repair. ${ }^{20}$ However, when an aneurysm presents complex characteristics, such as an intraluminal thrombus, mycotic or infectious etiology, atherosclerotic or calcified neck, nonsaccular morphology, and incorporation of perforators, complete surgical clipping is infeasible or at least notoriously difficult. ${ }^{26}$ In those circumstances, cerebral revascularization must be considered as an al- ternative method that depends on the aneurysm location, LSA anatomy, and rupture status.

Recently, intracranial-to-intracranial bypass has been widely used for its simpler and less invasive characteristic. ${ }^{18,30,31}$ At the same time, several potential shortcomings including anatomical constraints and technical demands should be considered. Besides, the frequent involvement of perforators, as in most cases in this study, may prohibit this technique from being indicated for proximal MCA aneurysms. However, in situ side-to-side bypass is particularly attractive for arterial reconstruction of distal MCA $\left(\mathrm{M}_{2}\right.$ or $\mathrm{M}_{3}$ [opercular segment of the MCA]) arborization because this technique eliminates the need for graft harvesting or the further dissection of extracranial donor vessels. Meanwhile, the low flow volume is adequate for the blood replacement of distal vasculatures..$^{30}$

The EC-IC bypass is a well-established method for treating complex aneurysms and is often performed in combination with a trapping strategy. Proximal occlusion, as a subtype of partial trapping, is preferred for producing a retrograde flow from the distal part of the aneurysm and facilitating intraaneurysmal thrombosis. Complete trapping may be the best alternative for aneurysms free of 


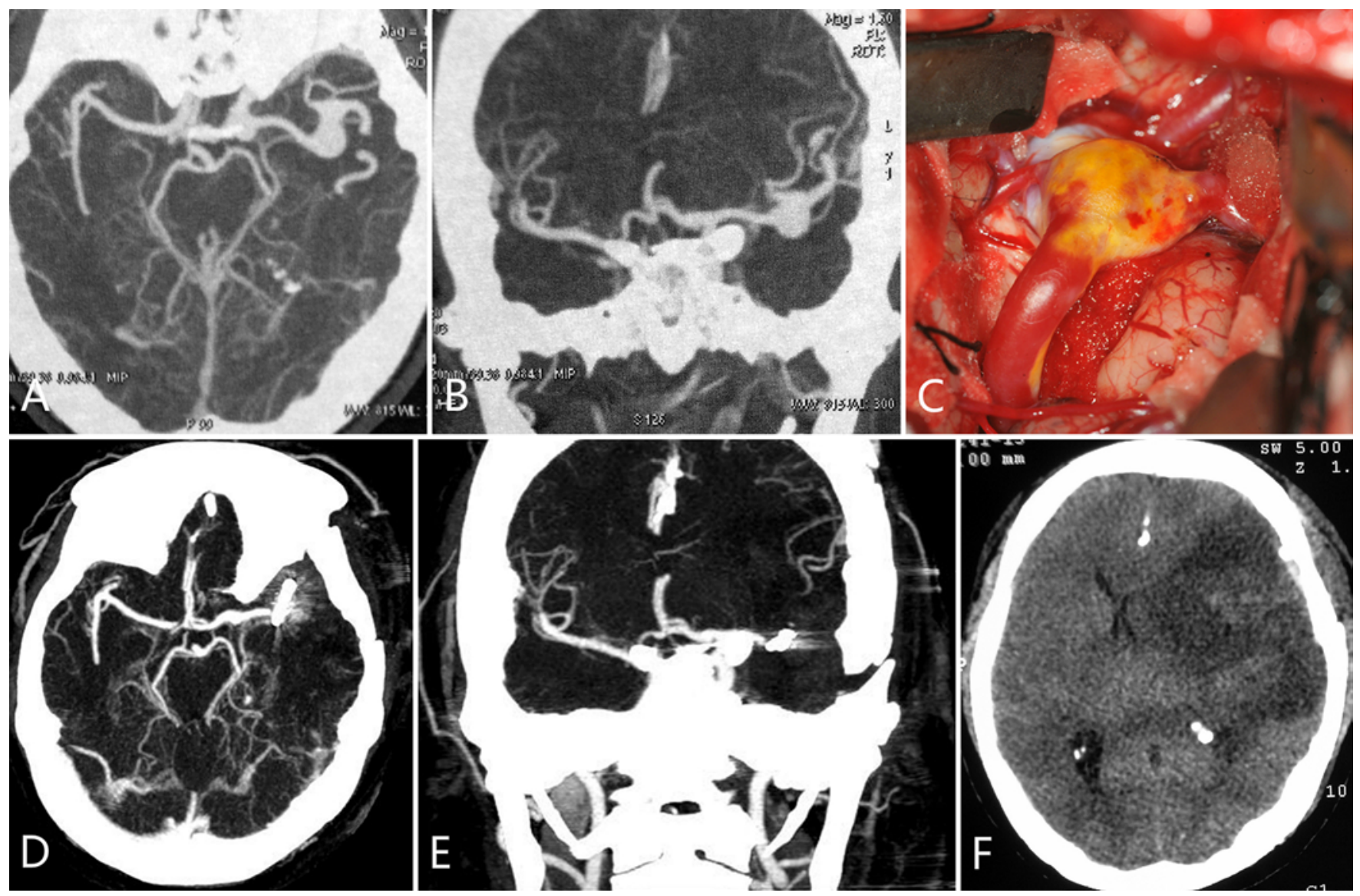

FIG. 4. Preoperative axial (A) and coronal (B) CTA illustrated an MCA bifurcation aneurysm. Intraoperative photograph showing atherosclerotic characteristics of the lesion (C). The patent graft was not observed on postoperative angiography (D and E) studies, and left frontotemporal ischemia was detected (F).

perforating vessels. In rare cases, efferent outflow occlusion may be preferable when the afferent artery is difficult to reach and sacrifice, ${ }^{8,15,16}$ although negative results have been documented in the literature..$^{23}$ In addition, AR may be implemented following vascular reconstruction for debulking purposes. ${ }^{10}$

\section{The Role of IMA Bypass in Cerebral Revascularization}

Superficial temporal artery (STA)-MCA bypass is the standard type of cerebral revascularization. However, insufficient blood flow may result in negative events following therapeutic occlusion of the main trunk arteries that should be replaced by high-flow revascularization. Recently, the IMA bypass was redefined as a new "workhorse" in the field of high-flow bypass to replace conventional cervical artery bypass, ${ }^{14,29}$ in which long-term grafts are prone to kink subcutaneously and second-site incision is mandatory.

However, complex and traumatic donor vessel harvesting that required zygomatic osteotomy or middle fossa removal during the IMA bypass discouraged broader acceptance of this technique into neurosurgical practice. Recently, a less invasive method without bone sacrifice to identify $I_{2}$ was proposed. ${ }^{19,21,39}$ Meanwhile, new bone landmarks to locate $I_{2}$ in a simpler and more efficient way were also introduced by conducting surgical simulation in cadavers. However, we should keep in mind that the working space on a fixed cadaver head is wider than that of a live patient because cadaver tissue is stiff and atrophied ${ }^{38}$ Notably, the only clinical case presented by the investigators had received 2 previous procedures, and the middle fossa had been partially removed before IMA bypass. ${ }^{39}$ Therefore, this is not the truly minimally invasive IMA bypass operation as defined. Meanwhile, regarding the issues of severe postoperative pain and chewing difficulties, no patient complained of fullness and discomfort of the temporal region in the current study. From our clinical experience after performing 130 cases of IMA bypass, exposing $\mathrm{I}_{2}$ without bone sacrifice is not reasonable and is extremely difficult due to obstruction by the temporalis muscle. Our position is that a comparative study of the advantages and limitations of each exposure technique should be conducted in the near future.

As for the interposition graft of IMA bypass, the RA $^{24,25,32-34,36}$ and forearm cephalic vein ${ }^{12,13}$ have been used in clinical settings. Recently, preclinical studies focusing on STA trunk grafts have been comprehensively reported in the literature. 1,9,21,27 However, its diameter mismatch with donor vessels and the short length available for approaching EC-IC vessels make tension-free reconstruction 
difficult. ${ }^{35,37}$ Notably, an article with "STA graft" in its title included the only case of IMA bypass with RA graft. ${ }^{9}$ We highly recommend that RA be used as the preferred graft in IMA bypass procedures by virtue of suitable arterial diameter and adequate graft length. Meanwhile, the synchronous performance of craniotomy and graft harvesting by 1 primary surgeon and 2 assistants makes the procedure less time-consuming. The forearm cephalic vein is another valid option for those who fail the Allen test. The STA trunk may only be considered when other reliable grafts are not available. Therefore, IMA bypass with $\mathrm{RA}$ following bone drilling remains the benchmark in this novel bypass surgery.

\section{Limitations of the Study}

The main inherent limitation of this study was the retrospective nature of the data analysis, which leads to potential ascertainment bias. Besides, the limited number of patients may have precluded a firm conclusion regarding the safety and efficacy of IMA bypass for treating CMCAAs. In addition, this study was not a randomized controlled trial, which is another limitation. Further studies with more cases and a control group are necessary to confirm our findings. Our results also reflected the experience of a single surgeon who used a defined set of protocols at a single center, which may not be representative of the neurosurgical cases in other large academic centers and may limit the generalizability of the data.

\section{Conclusions}

The satisfactory results in the present study demonstrate the feasibility of treating CMCAAs by using an IMA bypass procedure; the rates of periprocedural complications and morbidity were acceptable, and the efficacy of the surgery was high. This novel arterial reconstruction procedure is a promising method for complex cerebrovascular cases and should be kept in the armamentarium of neurosurgeons. However, intraoperative radical aneurysm resection or inappropriate recipient site selection should be avoided in this subtype of MCA aneurysm. Despite advances in endovascular and neurointerventional techniques, EC-IC bypass remains an essential solution and, indeed, the dominant option when performed by experienced hands.

\section{Acknowledgments}

We received financial support from the Beijing Municipal Natural Science Foundation (Grant No. 7161005 to X.S.) and the Science and Technology Commission Foundation of Beijing (Grant No. Z161100000516019 to X.S.).

Long Wang expresses his sincere gratitude to Xiang'en Shi for supporting him as a clinical research fellow at Barrow Neurological Institute and an advanced training fellow in Sapporo Teishinkai Hospital. He also thanks his beloved parents, Yan Wu and Haige Wang, for their gracious consideration and great confidence during his entire 29 years of life. Finally, he appreciates the invaluable support and companionship he has received from his wife Lujun Jing over the last 5 years.

\section{References}

1. Benet A, Meybodi AT, Feng X, Lawton MT: Internal maxil- lary artery to M2 middle cerebral artery bypass with modified superficial temporal artery graft: 3-dimensional operative video. Oper Neurosurg (Hagerstown) 13:280, 2017

2. Brinjikji W, Cloft HJ, Fiorella D, Lanzino G, Kallmes DF: Estimating the proportion of intracranial aneurysms likely to be amenable to treatment with the pipeline embolization device. J Neurointerv Surg 5:45-48, 2013

3. Britz GW: Flow diversion is not yet the complete package. World Neurosurg 82:1005-1006, 2014

4. Chalouhi N, Jabbour P, Singhal S, Drueding R, Starke RM, Dalyai RT, et al: Stent-assisted coiling of intracranial aneurysms: predictors of complications, recanalization, and outcome in 508 cases. Stroke 44:1348-1353, 2013

5. Darsaut TE, Bing F, Makoyeva A, Gevry G, Salazkin I, Raymond J: Flow diversion of giant curved sidewall and bifurcation experimental aneurysms with very-low-porosity devices. World Neurosurg 82:1120-1126, 2014

6. Darsaut TE, Bing F, Salazkin I, Gevry G, Raymond J: Flow diverters failing to occlude experimental bifurcation or curved sidewall aneurysms: an in vivo study in canines. J Neurosurg 117:37-44, 2012

7. Elsharkawy A, Lehečka M, Niemelä M, Billon-Grand R, Lehto H, Kivisaari R, et al: A new, more accurate classification of middle cerebral artery aneurysms: computed tomography angiographic study of 1,009 consecutive cases with 1,309 middle cerebral artery aneurysms. Neurosurgery 73:94-102, 2013

8. Esposito G, Fierstra J, Regli L: Distal outflow occlusion with bypass revascularization: last resort measure in managing complex MCA and PICA aneurysms. Acta Neurochir (Wien) 158:1523-1531, 2016

9. Feng X, Meybodi AT, Rincon-Torroella J, El-Sayed IH, Lawton MT, Benet A: Surgical technique for high-flow internal maxillary artery to middle cerebral artery bypass using a superficial temporal artery interposition graft. Oper Neurosurg (Hagerstown) 13:246-257, 2017

10. Lan J, Fu ZY, Zhang JJ, Ma C, Cao CJ, Zhao WY, et al: Giant serpentine aneurysm of the middle cerebral artery. World Neurosurg 117:109-114, 2018

11. Matsukawa H, Kamiyama H, Miyazaki T, Kinoshita Y, Ota N, Noda K, et al: Surgical treatment of middle cerebral artery aneurysms: aneurysm location and size ratio as risk factors for neurologic worsening and ischemic complications. World Neurosurg 117:e563-e570, 2018

12. Nossek E, Costantino PD, Chalif DJ, Ortiz RA, Dehdashti AR, Langer DJ: Forearm cephalic vein graft for short, "middle"-flow, internal maxillary artery to middle cerebral artery bypass. Oper Neurosurg (Hagerstown) 12:99-105, 2016

13. Nossek E, Costantino PD, Eisenberg M, Dehdashti AR, Setton A, Chalif DJ, et al: Internal maxillary artery-middle cerebral artery bypass: infratemporal approach for subcranialintracranial (SC-IC) bypass. Neurosurgery 75:87-95, 2014

14. Nossek E, Langer DJ: Internal maxillary artery to middle cerebral artery cranial bypass: the new "work horse" for cerebral flow replacement. World Neurosurg 115:44-46, 2018

15. Nussbaum ES: Surgical distal outflow occlusion for the treatment of complex intracranial aneurysms: experience with 18 cases. Neurosurgery 11 (Suppl 2):8-16, 2015

16. Nussbaum ES, Madison MT, Goddard JK, Lassig JP, Janjua TM, Nussbaum LA: Remote distal outflow occlusion: a novel treatment option for complex dissecting aneurysms of the posterior inferior cerebellar artery. Report of 3 cases. J Neurosurg 111:78-83, 2009

17. Nussbaum ES, Madison MT, Goddard JK, Lassig JP, Kallmes KM, Nussbaum LA: Microsurgical treatment of unruptured middle cerebral artery aneurysms: a large, contemporary experience. J Neurosurg [epub ahead of print June 1, 2018. DOI: 10.3171/2018.1.JNS172466]

18. Qian H, Wang L, Brooks KS, Zhao X, Shi X, Lei T: MCA- 
to-MCA bypass with interposition graft for ruptured mycotic middle cerebral artery aneurysm. World Neurosurg 122:195, 2019

19. Rodriguez Rubio R, Kola O, Tayebi Meybodi A, Tabani H, Feng X, Burkhardt JK, et al: Minimally invasive exposure of the maxillary artery at the anteromedial infratemporal fossa. Oper Neurosurg (Hagerstown) 16:79-85, 2019

20. Rodríguez-Hernández A, Sughrue ME, Akhavan S, Habdank-Kolaczkowski J, Lawton MT: Current management of middle cerebral artery aneurysms: surgical results with a "clip first" policy. Neurosurgery 72:415-427, 2013

21. Rubio RR, Gandhi S, Benet A, Tabani H, Burkhardt JK, Kola O, et al: Internal maxillary artery to anterior circulation bypass with local interposition grafts using a minimally invasive approach: surgical anatomy and technical feasibility. World Neurosurg 120:e503-e510, 2018

22. Saleme S, Iosif C, Ponomarjova S, Mendes G, Camilleri Y, Caire F, et al: Flow-diverting stents for intracranial bifurcation aneurysm treatment. Neurosurgery 75:623-631, 2014

23. Shakur SF, Carlson AP, Harris D, Alaraj A, Charbel FT: Rupture after bypass and distal occlusion of giant anterior circulation aneurysms. World Neurosurg 105:1040.e7-1040. e13, 2017

24. Shi X, Qian H, Fang T, Zhang Y, Sun Y, Liu F: Management of complex intracranial aneurysms with bypass surgery: a technique application and experience in 93 patients. Neurosurg Rev 38:109-120, 2015

25. Shi X, Qian H, K C KI, Zhang Y, Zhou Z, Sun Y: Bypass of the maxillary to proximal middle cerebral artery or proximal posterior cerebral artery with radial artery graft. Acta Neurochir (Wien) 153:1649-1655, 2011

26. Tayebi Meybodi A, Huang W, Benet A, Kola O, Lawton MT: Bypass surgery for complex middle cerebral artery aneurysms: an algorithmic approach to revascularization. J Neurosurg 127:463-479, 2017

27. Tayebi Meybodi A, Lawton MT, Rodriguez Rubio R, Yousef $\mathrm{S}$, Guo X, Feng X, et al: Internal maxillary artery to upper posterior circulation bypass using a superficial temporal artery graft: surgical anatomy and feasibility assessment. World Neurosurg 107:314-321, 2017

28. Topcuoglu OM, Akgul E, Daglioglu E, Topcuoglu ED, Peker A, Akmangit I, et al: Flow diversion in middle cerebral artery aneurysms: is it really an all-purpose treatment? World Neurosurg 87:317-327, 2016

29. Wang L, Cai L, Lu S, Qian H, Lawton MT, Shi X: The history and evolution of internal maxillary artery bypass. World Neurosurg 113:320-332, 2018

30. Wang L, Cai L, Qian H, Lawton MT, Shi X: The in situ sideto-side bypass technique: a comprehensive review of the technical characteristics, current anastomosis approaches, and surgical experience. World Neurosurg 115:357-372, 2018

31. Wang L, Cai L, Qian H, Tanikawa R, Lawton M, Shi X: The re-anastomosis end-to-end bypass technique: a comprehen- sive review of the technical characteristics and surgical experience. Neurosurg Rev [epub ahead of print], 2018

32. Wang L, Lu S, Qian H, Shi X: Internal maxillary artery bypass with radial artery graft treatment of giant intracranial aneurysms. World Neurosurg 105:568-584, 2017

33. Wang L, Lu S, Qian H, Shi X: Internal maxillary bypass for complex pediatric aneurysms. World Neurosurg 103:395403, 2017

34. Wang L, Shi X, Liu F, Qian H: Bypass surgery to treat symptomatic fusiform dilation of the internal carotid artery following craniopharyngioma resection: report of 2 cases. Neurosurg Focus 41(6):E17, 2016

35. Wang L, Shi X, Qian H: Feasibility of using a superficial temporal artery graft in internal maxillary artery bypass. World Neurosurg 108:971-972, 2017

36. Wang L, Shi X, Qian H: Flow reversal bypass surgery: a treatment option for giant serpentine and dolichoectatic aneurysms-internal maxillary artery bypass with an interposed radial artery graft followed by parent artery occlusion. Neurosurg Rev 40:319-328, 2017

37. Wang L, Shi X, Qian H: Graft selection in high-flow internal maxillary artery bypass. Oper Neurosurg (Hagerstown) 14:10-11, 2018 (Letter)

38. Wang L, Shi X, Qian H: Is internal maxillary artery bypass feasible without zygomatic osteotomy? World Neurosurg 104:1004, 2017 (Letter)

39. Yağmurlu K, Kalani MYS, Martirosyan NL, Safavi-Abbasi S, Belykh E, Laarakker AS, et al: Maxillary artery to middle cerebral artery bypass: a novel technique for exposure of the maxillary artery. World Neurosurg 100:540-550, 2017

40. Zanaty M, Chalouhi N, Tjoumakaris SI, Gonzalez LF, Rosenwasser R, Jabbour P: Flow diversion for complex middle cerebral artery aneurysms. Neuroradiology 56:381-387, 2014

\section{Disclosures}

Dr. Tanikawa holds patents with Medical U \& A and Takayama.

\section{Author Contributions}

Conception and design: Wang. Acquisition of data: Shi, Wang, Lu, Qian. Analysis and interpretation of data: Wang. Drafting the article: Wang, Cai. Critically revising the article: Wang. Reviewed submitted version of manuscript: Shi, Wang. Approved the final version of the manuscript on behalf of all authors: Shi. Statistical analysis: Shi, Wang. Administrative/technical/material support: Shi, Wang, Qian, Tanikawa. Study supervision: Shi, Tanikawa.

\section{Correspondence}

Xiang'en Shi: SanBo Brain Hospital, Capital Medical University, Beijing, China. shixen@sina.com. 